\title{
One-dimensional Peptide Mapping of the Subunits of Pertussis Toxin
}

\author{
By V. Y. PERERA, * H. ROGERS AND J. H. FREER \\ Department of Microbiology, University of Glasgow, Alexander Stone Building, Garscube Estate, \\ Glasgow G61 IQH, UK
}

(Received 17 December 1984; revised 27 March 1985)

\begin{abstract}
Pertussis toxin (pertussigen) purified from the cytoplasmic fraction of Bordetella pertussis strain 18334, phase 1, consisted of five subunits which included an additional subunit (S1a) not previously reported. Subunits S1, S1a and S2 showed extensive structural homology when analysed by one-dimensional peptide mapping, indicating that the latter two were probably derived from proteolytic cleavage of the largest subunit, S1. Subunits S3 and S4,5 generated only a limited number of peptides following chemical and enzymic degradation, but these subunits differed structurally from each other and from those showing structural homology.
\end{abstract}

\section{INTRODUCTION}

Toxigenic strains of Bordetella pertussis phase 1 consistently produce three distinct toxins: the heat-labile toxin, the lipopolysaccharide endotoxin and pertussis toxin (PT) (Wardlaw \& Parton, 1983). Pertussis toxin has many biological activities, which include sensitization to histamine (Munoz \& Bergman, 1968), promotion of lymphocytosis and leucocytosis (Arai \& Sato, 1976; Morse \& Morse, 1976), activation of pancreatic islets (Katada \& Ui, 1977) and haemagglutinating activity (Irons \& MacLennan, 1979). Recently, toxin-mediated ADPribosylation of mammalian cell membrane proteins was demonstrated by Katada \& Ui (1982).

Many of the subunit-toxins with ADP-ribosyl transferase activity produced by other organisms consist of two components: the A (active) moiety with ADP-ribosyl transferase activity, and the B (binding) moiety (Gill, 1978). The B moiety generally consists of either a single peptide, as in diphtheria toxin (Collier, 1975), or five identical subunits, as with cholera toxin (Gill, 1976) and heat-labile enterotoxin of Escherichia coli (Gill et al., 1981). Recently, Tamura et al. (1982) reported that PT was an oligomeric protein consisting of an A protomer (S1) with ADP-ribosyl transferase activity and a $B$ oligomer which promoted the binding of the native toxin to receptor molecules. However, unlike other subunit-toxins, the B oligomer of PT was reported to consist of four dissimilar subunits, S2, S3, S4 and S5.

The object of this study was to investigate the possible structural relationship of the various subunits of PT by means of one-dimensional peptide mapping and to determine whether the structure of this toxin conformed with the A-B model proposed for other bacterial toxins.

\section{METHODS}

Organism and growth conditions. B. pertussis strain 18334, phase 1, was grown in shaken (150 cycles $\left.\mathrm{min}^{-1}\right)$ cyclodextrin liquid medium (Imaizumi et al., 1983) for $48 \mathrm{~h}$ at $37^{\circ} \mathrm{C}$. Bacteria from 101 medium were harvested by centrifugation at $10000 \mathrm{~g}$ for $30 \mathrm{~min}$ and used for purification of cell-associated PT.

Partial purification of PT. Bacteria ( $150 \mathrm{~g}$ wet wt) were disrupted by a single passage through a French press at 2000 bar and envelope fragments were removed by centrifugation at $30000 \mathrm{~g}$ for $1 \mathrm{~h} \mathrm{at} 4{ }^{\circ} \mathrm{C}$. PT in the cytoplasmic fraction was partially purified by affinity chromatography on a Fetuin-Sepharose 4B column based on the method

Abbreviations: NCS, $N$-chlorosuccinimide; PT, pertussis toxin; TLCK, $N$-tosyl-L-phenylalanine chloromethyl ketone. 
described by Sekura et al. (1983). Bound toxin was eluted with $0 \cdot 1 \mathrm{M}-\mathrm{Tris}, 0 \cdot 5 \mathrm{M}-\mathrm{NaCl}, \mathrm{pH} 10 \cdot 0$, containing $3 \mathrm{M}-$ KSCN (Cowell et al., 1979), the eluate immediately brought to $\mathrm{pH} 7.5$ with $1.0 \mathrm{M}-\mathrm{HCl}$ and the toxin concentrated by ultrafiltration using a YM30 membrane (Amicon). The retentate was then dialysed for $16 \mathrm{~h}$ against 100 vols $0 \cdot 01 \mathrm{M}$-phosphate, $0 \cdot 15 \mathrm{M}-\mathrm{NaCl}, \mathrm{pH} 7 \cdot 4$. The yield of toxin was approximately $10 \mathrm{mg}$.

Isolation of subunits by sodium dodecyl sulphate-polyacrylamide gel electrophoresis (SDS-PAGE). Affinity-purified PT (approximately $500 \mu \mathrm{g}$ ) was solubilized in buffer containing $1.5 \%(\mathrm{w} / \mathrm{v})$ SDS and $2.5 \%(\mathrm{v} / \mathrm{v}) 2$-mercaptoethanol and the subunits were separated by SDS-PAGE (Laemmli, 1970) at a constant current of $40 \mathrm{~mA}$ using a $15 \%(\mathrm{w} / \mathrm{v})$ acrylamide resolving gel. The subunits were visualized by staining briefly with Coomassie brilliant blue R250 (Cleveland et al., 1977) and each of the stained bands was excised and stored at $-20^{\circ} \mathrm{C}$.

One-dimensional peptide mapping. Gel slices (each of 7-10 $\mu \mathrm{g}$ protein) were treated with $N$-chlorosuccinimide (NCS) in urea (Lischwe \& Ochs, 1982) and inserted into the wells of a $4 \%(\mathrm{w} / \mathrm{v})$ acrylamide stacking gel, and the peptides were separated on a $17 \%(\mathrm{w} / \mathrm{v})$ acrylamide resolving gel as above. Untreated slices were also electrophoresed in parallel for comparison.

Enzymic digestion of subunits was carried out according to Cleveland et al. (1977) with either staphylococcal V8 proteinase (EC 3.4.21 .19; Miles Laboratories) or TLCK-treated $\alpha$-chymotrypsin (EC 3.4.21 .1; Sigma). Each enzyme $(1.0 \mu \mathrm{g})$ was added to the well containing the gel slice and limited proteolysis was allowed to take place in the stacking gel by electrophoresing at $10 \mathrm{~mA}$ until the dye marker reached the bottom of the stacking gel. The peptide fragments generated subsequently separated in a $17 \%(\mathrm{w} / \mathrm{v})$ acrylamide gel at a constant current of $40 \mathrm{~mA}$.

Molecular mass markers (Sigma) used were bovine serum albumin (68 kDal), ovalbumin (45 kDal), glyceraldehyde-3-phosphate dehydrogenase $(36 \mathrm{kDal})$, carbonic anhydrase (29 kDal), trypsinogen (24 kDal), trypsin inhibitor $(20 \cdot 1 \mathrm{kDal})$ and $\beta$-lactalbumin $(14 \cdot 2 \mathrm{kDal})$. The gels were stained with silver according to the method described by Oakley et al. (1980).

\section{RESULTS AND DISCUSSION}

The SDS-PAGE patterns of reduced PT and isolated subunits are shown in Fig. $1(a, b)$ and the apparent molecular masses of the subunits are summarized in Table 1. Under the conditions used, subunits $\mathrm{S} 4$ and $\mathrm{S} 5$ were not separable and instead a single peptide band corresponding to an apparent molecular mass of $14 \mathrm{kDal}$ was detected. This peptide (henceforth referred to as S4,5) was also reported by Sekura et al. (1983). This effect was not peculiar to the toxin preparation used in this study since examination under identical conditions of purified PT kindly provided by M. Ui (Dept of Physiological Chemistry, Hokkaido University, Japan) and by A. Robinson (PHLS CAMR, Porton Down, Salisbury, UK) failed to show any separation of the two subunits (data not shown). The other major subunits detected were S1, S2 and S3 with apparent molecular masses of $28,24.5$ and $23.5 \mathrm{kDal}$, respectively, values similar to those reported by Tamura et al. (1982) and Sekura et al. (1983). A fifth subunit referred to as S1a and having an apparent molecular mass of $26 \mathrm{kDal}$ was also detectable between $\mathrm{S} 1$ and $\mathrm{S} 2$. This subunit has not been reported by other workers.

Treatment of S1 and S1 a with NCS in urea generated fragments $a, b, c, d$ and $e$ and $c, d, e, g$ and $j$ respectively (Fig. 2 , lanes 1,2$)$ of which three peptides $(c, d$ and $e$ ) were common to both subunits. Degradation of S2 with this reagent produced three major fragments, $g, i$ and $j$ (lane 3 ). Two of these fragments ( $g$ and $j$ ) were detected from S1a. Enzymic degradation of S1, S1a and S2 with $\alpha$-chymotrypsin produced the following fragments: $a, b, d, e$ and $f ; b, d, e$ and $f$; and $b, d$ and $e$ respectively (Fig. 3, lanes 1, 2 and 3) of which three fragments $(b, d$ and $e$ ) were common to all three subunits. In addition, fragment $f$ was common to $\mathrm{S} 1$ and S1a. Fragments common to all three subunits were also generated by digestion with staphylococcal V8 proteinase (data not shown). Such homology shown by the peptide maps of S1, S1 a and S2 subunits was indicative of the structural relationship of the latter two polypeptides with the catalytic subunit S1 (the A moiety) of PT. Subunits S1a and S2 may be degradation products of S1 produced by the action of $B$. pertussis proteolytic enzymes which can be detected in both cytoplasmic fractions and culture supernates (unpublished observations). The observation that subunit S1a was markedly diminished in PT purified from culture supernates (unpublished observations) supports the suggestion that this subunit was a partially degraded form of S1 and that full conversion to S2 possibly occurred either during or after release of the toxin into the culture medium. Cleavage of S3 with NCS reagent (Fig. 2, lane 4) generated only two fragments $(f$ and $h$ ), which differed from those of S1, S1a and S2. Low molecular mass degradation products of S4,5 were not detected 


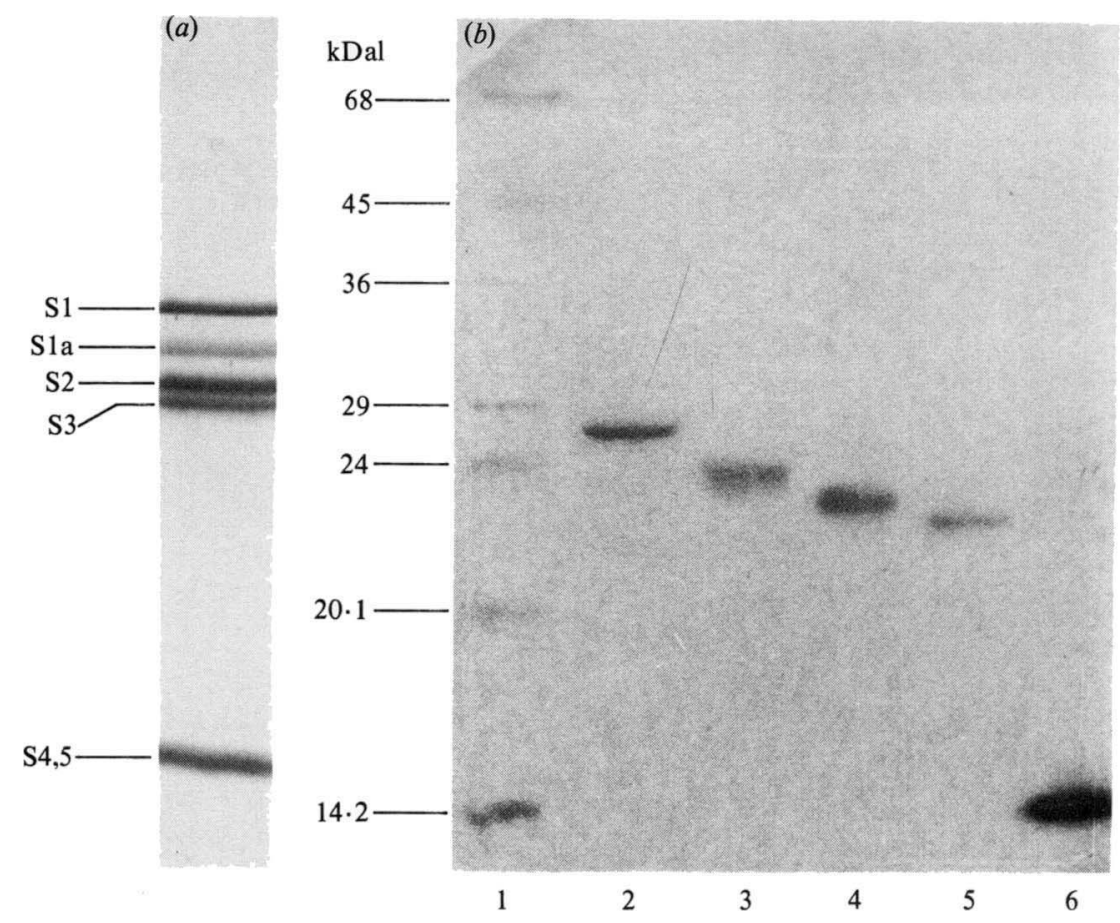

Fig. 1. SDS-PAGE of $(a)$ partially purified PT, and $(b)$ gel slices containing toxin subunits. Lane 1 shows molecular mass marker proteins and lanes 2-6 show S1, S1a, S2, S3 and S4,5 respectively.

Table 1. Comparison of the apparent molecular mass of the subunits of PT when examined by $S D S-P A G E$

$\begin{array}{rcccccccc}\text { Subunit ... } & \overbrace{\text { S1 }}^{\text {Apparent }} & \text { S1a } & \text { S2 } & \text { S3 } & \text { S4 } & \text { S5 } & \text { S4,5 } & \text { Reference } \\ & 28.0 & 26.0 & 24.5 & 23.5 & - & - & 14.0 & \text { This study } \\ 28.0 & - & 23.0 & 22.0 & 11.7 & 9.3 & - & \text { Tamura } \text { et al. (1982) } \\ 30.0 & - & 26.1 & 25.4 & - & - & 13.9 & \text { Sekura } \text { et al. (1983) }\end{array}$

(Fig. 2, lane 5). The susceptibility of all the subunits to degradation by NCS in urea was indicative of the presence of tryptophan residues (Lischwe \& Ochs, 1982). Degradation of S3 with $\alpha$-chymotrypsin produced only one major fragment (c) (Fig. 3, lane 4). This, as well as the fragments generated with staphylococcal V8 proteinase (data not shown) were unique to this particular subunit. Much of the native S4,5 remained undegraded following treatment with $\alpha$ chymotrypsin (Fig. 3, lane 5) and staphylococcal V8 proteinase (data not shown). The absence of homology between the peptide maps of S1, S3 and S4,5 suggests that these subunits share no homologous amino acid sequences and were therefore the products of different precursors. The B moiety of PT thus consisted of at least two or possibly three dissimilar subunits.

In conclusion, one-dimensional peptide mapping of the subunits of cell-associated PT revealed three structurally related subunits but the subunit structure of the toxin appears more complex than that of other bacterial toxins with similar enzymic activity.

We thank Ian Mackie for photographic assistance. This work was supported by MRC Grant no. G 8306837 SB. 

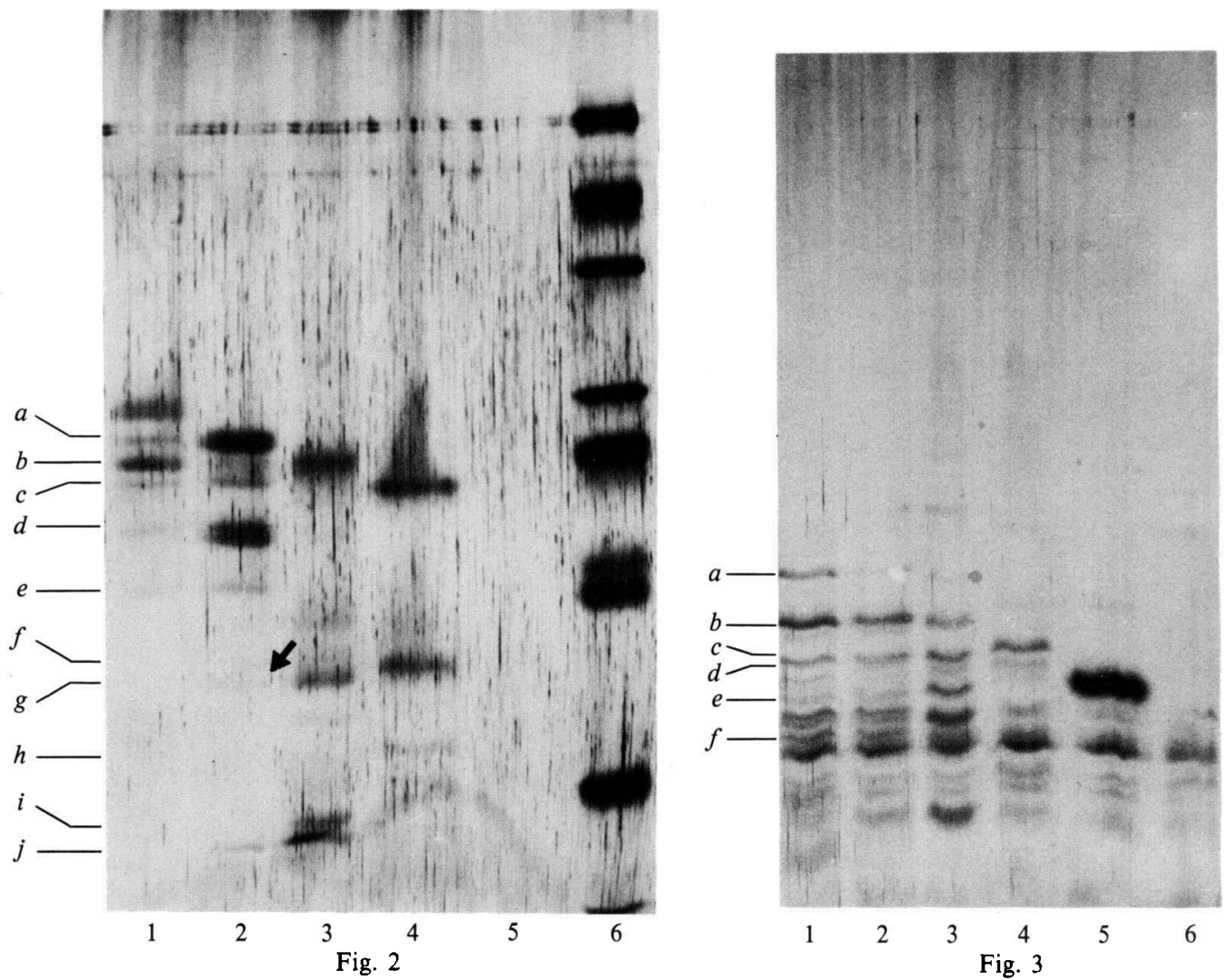

Fig. 2. Cleavage of the subunits of PT with NCS reagent. Lanes 1-5 show cleaved S1, S1a, S2, S3 and S4,5 respectively and lane 6 shows molecular mass markers as for Fig. 1(b). Fragments $a$ to $j$ were generated by subunits S1, S1a, S2 and S3. See text for details. Fragment $g$ in lane 2 (faint band) is arrowed.

Fig. 3. SDS-PAGE of the subunits digested with $\alpha$-chymotrypsin. Lanies $1-5$ show digests of S1, S1a, $\mathrm{S} 2, \mathrm{~S} 3$ and S4,5 respectively and lane 6 shows enzyme alone. Fragments $a$ to $f$ were generated by subunits S1, S1a, S2 and S3. See text for details.

\section{REFERENCES}

ARAI, H. \& SATO, Y. (1976). Separation and characterization of the distinct haemagglutinins contained in purified leukocytosis-promoting factor from Bordetella pertussis. Biochimica et biophysica acta 444, 765782.

Cleveland, D. W., Fischer, S. G., Kirschner, M. W. \& Laemml, U. K. (1977). Peptide mapping by limited proteolysis in sodium dodecyl sulfate and analysis by gel electrophoresis. Journal of Biological Chemistry 252, 1102-1106.

Collier, R. J. (1975). Diphtheria toxin: mode of action and structure. Bacteriological Reviews 39, 5485.

Cowell, J. L., Sato, Y., Sato, H., AN Der Lan, B. \& MANCLARK, C. R. (1979). Separation, purification, and properties of the filamentous haemagglutinin and the leukocytosis promoting factor-haemagglutinin from Bordetella pertussis. In International Symposium on Pertussis, pp. 371-379. Edited by C. R.
Manclark \& J. C. Hill. DHEW publication no. 791830. Washington, DC: United States Government Printing Office.

GiLL, D. M. (1976). The arrangement of subunits in cholera toxin. Biochemistry 15, 1242-1248.

GiLL, D. M. (1978). Seven toxic peptides that cross cell membranes. In Bacterial Toxins and Cell Membranes, pp. 291-332. Edited by J. Jeljaszewicz \& T. Wadström. London: Academic Press.

Gill, D. M., Clements, J. D., Robertson, D. C. \& Finkelstein, R. A. (1981). Subunit number and arrangement in Escherichia coli heat-labile enterotoxin. Infection and Immunity 33, 677-682.

Imaizumi, A., Suzuki, Y., Ono, S., Sato, H. \& Sato, Y. (1983). Effect of heptakis(2,6- $O$-dimethyl)- $\beta$ cyclodextrin on the production of pertussis toxin by Bordetella pertussis. Infection and Immunity 41, 11381143.

Irons, L. I. \& MACLENNAN, A. P. (1979). Isolation of 
the lymphocytosis promoting factor-haemagglutinin of Bordetella pertussis by affinity chromatography. Biochimica et biophysica acta 580, 175-185.

Katada, T. \& Ui, M. (1977). Perfusion of the pancreas isolated from pertussis-sensitized rats: potentiation of insulin secretory responses due to $\beta$-adrenergic stimulation. Endocrinology 101, 1247-1255.

KATADA, T. \& Ui, M. (1982). ADP-ribosylation of the specific membrane protein of $\mathrm{C} 6$ cells by isletactivation protein associated with modification of adenylate cyclase activity. Journal of Biological Chemistry 257, 7210-7216.

LAEMMLI, U. K. (1970). Cleavage of structural proteins during the assembly of the head of bacteriophage T4 . Nature, London 227, 680-685.

Lischwe, M. A. \& OCHS, D. (1982). A new method for partial peptide mapping using $N$-chlorosuccinimide/ urea and peptide silver staining in sodium dodecyl sulfate-polyacrylamide gels. Analytical Biochemistry 127, 453-457.

MORSE, S. I. \& MORSE, J. H. (1976). Isolation and properties of the leukocytosis and lymphocytosis- promoting factor of Bordetella pertussis. Journal of Experimental Medicine 143, 1483-1502.

Munoz, J. J. \& Bergman, R. K. (1968). Histaminesensitising factors from microbial agents, with special reference to Bordetella pertussis. Bacteriological Reviews 32, 103-126.

OAKLEY, B. R., KIRSCH, D. R. \& MORRIS, N. R. (1980). A simplified ultrasensitive silver stain for detection of proteins in polyacrylamide gels. Analytical Biochemistry 105, 361-363.

Sekura, R. D., Fish, F., Manclark, C. R., Meade, B. \& ZhanG, Y.-L. (1983). Pertussis toxin: affinity purification of a new ADP-ribosyltransferase. Journal of Biological Chemistry 258, 14647-14651.

Tamura, M., Nogmori, K., Murai, S., Yajima, M., Ito, K., Katada, T. \& UI, M. (1982). Subunit structure of islet activating protein, pertussis toxin, in conformity with the A-B model. Biochemistry 21, 5516-5522.

Wardlaw, A. C. \& Parton, R. (1983). Bordetella pertussis toxins. Pharmacology and Therapeutics 19, $1-53$. 